\title{
Consciousness Field Theory
}

Paul Mocombe C*

West Virginia State University, The Mocombeian Foundation, Inc., Lauderhill, Florida, United States.

*Corresponding author: Paul Mocombe C, West Virginia State University, The Mocombeian Foundation, Inc., Lauderhill, Florida, United States.
Received Date: December 12, 2020

Published Date: January 08, 2021

Introduction

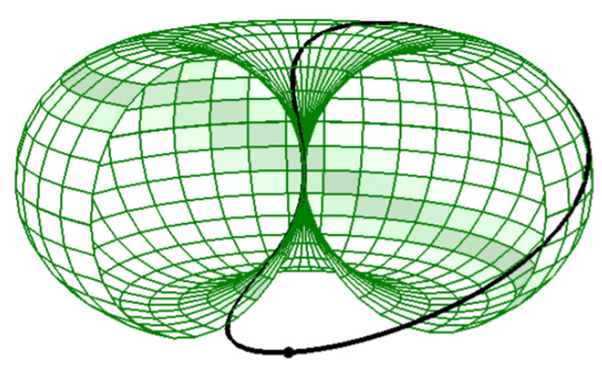

Figure 1: The univon mode; composed of a superluminal primordial information quantum (Sprinq). The mathematical horn torus surface on which the sprinq travels is cut away to show the interior. The black closed curve on the surface of the horn torus is the trajectory of univons sprinq (indicated by the black dot.).

$$
\begin{aligned}
& x(t)=R(1+\cos (\omega t)) \cos (\omega t) \\
& y(t)=R(1+\cos (\omega t)) \sin (\omega t) \\
& z(t)=R \sin (\omega t)
\end{aligned}
$$

$$
\begin{aligned}
& R=\hbar / M c=2.9 \times 10^{-97} \mathrm{~m} \\
& \omega=M c^{2} / \hbar=1.0 \times 10^{105} \text { radians } / \mathrm{s} \\
& M=\text { mass of observable universe }=1.2 \times 10^{54} \mathrm{~kg}
\end{aligned}
$$

Figure 2: The parametric equations of the univon model composed of a circulating sprinq. The calculated maximum speed of the circulating sprinq is $c \sqrt{5}=2.236 \mathrm{c}$ (at the equator of the mathematical torus) while its minimum speed is $c$ (at the center of the mathematical torus). 
Paul C. Mocombe's (2019) structurationist theory of phenomenological structuralism, building on and synthesizing a form of M-theory with, mathematical elements of univon multiverse hypothesis, the quantum computation of ORCH-OR theory, Black Hole Big Bang Theory (BHBBT), structurationism, and the multiverse ideas of Haitian ontology/epistemology and quantum mechanics abductively posits that spacetime is fundamental; and consciousness is an emergent fifth force of nature, a field of consciousness (the consciousness field-CF) composed of a quantum material substance/energy, psychion, the phenomenal property, qualia or informational content, of which is recycled/ replicated/entangled/superimposed throughout the multiverse and becomes embodied via the microtubules of neurons of brains and aggregate matter of multiple worlds to constitute mind (see Figures 1 and 2).

Mind (composed of the personal and collective unconscious, and the sense-experience of the emerging ego held together by the brain's electromagnetic field generated by the periodic discharge of neurons), in turn, is manifested in simultaneous, entangled, superimposed, and interconnecting material resource frameworks, multiple worlds, as praxis or practical consciousness of organic life, the content of which in-turn becomes the phenomenal properties, qualia, of material (subatomic particle energy, psychion) consciousness that is recycled/replicated/ entangled/superimposed via the consciousness field throughout the multiverses upon matter disaggregation (see Figure 3).

In other words, existence precedes essence; but essence is emergent and eternal, and comes to constitute a fifth force of nature, a field of consciousness for Being production (the consciousness field), through the phenomenal properties, qualia (personal and collective unconscious), of neuronal subatomic particles, psychion, which are recycled/replicated/superimposed/ entangled throughout the multiverse and give human actors their initial (essential) practical consciousness that they organize and reproduce in replicated, entangled, and superimposed material resource frameworks (see Figures 3 and 4).

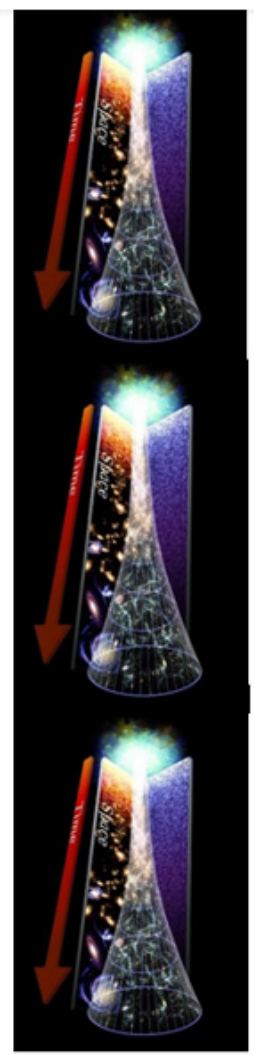

Figure 2: For Mocombe, building on BBBHT, the superverses with entangled and superimposed (via black holes) multiverses share the same informational content. So, the hypothesis here is that one superverse created a universe, and its informational content is entangled and superimposed on top of another superverse with the informational content of the previous universe emerging in it via black holes. Hence what you have are a layer of multiverses and superverses, superimposed and entangled, whose informational content are shared or recycled via black holes, which organize and structure the multiverses similarly. As such, quantum fluctuation and big bangs are constantly occurring and producing the same worlds, ad infinitum. So, when physicists look out to the cosmic microwave background (CMB), they are looking at the remnant from an early stage of our universe, which came forth from its older version a layer above it, and so on ad infinitum. Put more concretely, the physicists are in a superverse, of our universe, in our milky-way galaxy, looking out to the black hole of a milky-way galaxy from the superverse/multiverse above us. 


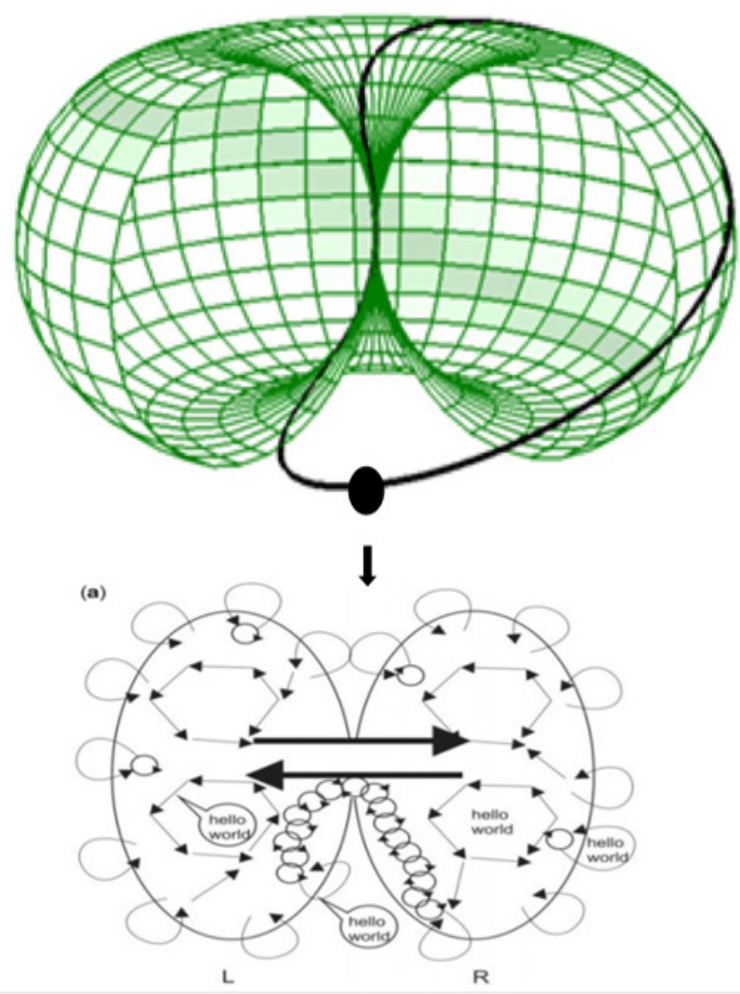

Figure 2: This figure represents how the psychions are embodied from the consciousness field (CF) in the microtubules of neurons of brains (figure a, adopted from McFadden, 2020, represents the human brain-left (L) and right (R) hemispheres-and its EM field, which holds together and integrates the qualia of psychions, informational content of the superverse/multiverses, which becomes individuated consciousness recursively organized and reproduced as practical consciousness), which produces an EM field that holds together and integrates the qualia of the psychions as individuated consciousness. For Mocombe, building on BBBHT, the superverses with entangled and superimposed (via black holes) multiverses share the same informational content. So, the hypothesis here is that one superverse created a universe, and its informational content is entangled and superimposed on top of another superverse with the informational content of the previous universe emerging in it via black holes. Hence what you have are a layer of multiverses and superverses, superimposed and entangled, whose informational contents are shared or recycled via black holes, which organize and structure the multiverses similarly. As such, quantum fluctuation and big bangs are constantly occurring and producing the same worlds, ad infinitum. The informational content, qualia, of these multiverses and worlds are encoded and transmitted as psychions and embodied in the microtubules of neurons of brains, which create an EM field that holds and integrates the psychions as individuated consciousness.

On this physics Mocombe builds his systemic philosophy, sociology, and psychology called, phenomenological structuralism. This work contrasts Paul C. Mocombe's (2019) consciousness field theory (CFT) of phenomenological structuralism (PS) with Johnjoe McFadden's (2020) conscious electromagnetic information theory (CEMI). The author posits a cognitive developmental psychology that is tied to PS's emergent logico-metaphysical materialist account regarding the constitution and perpetuation of the multiverse, consciousness, society, and the individual. Against CEMI, the author concludes that consciousness is an emergent force, a consciousness field of the universe, the subatomic particles, psychions, of which is received by the brain and integrated by its electromagnetic field [1-05].

\section{Background of the Problem}

Consciousness here refers to subjective awareness of phenomenal experiences, qualia, (ideology, language, self, feelings, choice, control of voluntary behavior, thoughts, etc.) of internal and external worlds. The academic literature "describes three possibilities regarding the origin and place of consciousness in the universe: (A) as an emergent property of complex brain neuronal computation, (B) as spiritual quality of the universe, distinct from purely physical actions, and (C) as composed of discrete 'proto-conscious' events acting in accordance with physical laws not yet fully understood" (Hameroff and Penrose, 2014, pg. 70). The latter position, (C), represents the ORCH-OR ("orchestrated objective reduction") theory of Stuart Hameroff and Roger Penrose (2014), which includes aspects of (A) and (B), and posits that "consciousness consists of discrete moments, each an 'orchestrated' quantum-computational process terminated by... an action [,objective reduction or $\mathrm{OR}$,] rooted in quantum aspects of the fine structure of space-time geometry, this being coupled to brain neuronal processes via microtubules" (pg. 70) [6-10]. In this view, the understanding is that a proto-conscious experience existed in the universe, panpsychism, and as a result of emergent structures of the brain it (proto-conscious experience, psychion) 
became embodied and evolved as a result of quantum neuronal computations of "brains". That is to say, in the protein structures, microtubules, of the neurons of the brain, which serves or acts like a quantum supercomputer, information and memories are stored and processed to orchestrate human conscious awareness. This latter position is neither pushing forth a spiritual understanding of consciousness as highlighted by physicists who view consciousness as emerging out of and seated in the electromagnetic field of the brain [11-15]; nor is it a dualist interpretation as found in the CEMI theory of Johnjoe McFadden (2020) who wants to hold on to the brain's neurons (material substance) and its electromagnetic field (energy/spiritual substance) as the generator and seat of consciousness, respectively. It is an underdeveloped materialist account of the origins and nature of consciousness in the multiverse.

For me, building on Paul C. Mocombe's (2018) structurationist theory with its basis in ORCH-OR theory, this conscious awareness, i.e., consciousness, is an emergent material substance, psychions, the phenomenal properties, qualia [16-20], of which becomes the mind (personal and collective unconscious and ego) of human actors expressed in entangled and superimposed multiple worlds as their practical activity or practical consciousness. In this Mocombeian (structurationist) view, consciousness is not fundamental; instead, it is an emergent (material) property of the multiverse, which is constituted and expressed, in the human sphere through subatomic particle aggregation, mode of production, language, ideology, ideological apparatuses, communicative discourse, and praxis. In this sense, Mocombe eliminates any spiritual elements (B) regarding consciousness constitution for a strict materialist perspective, which does not solely attribute consciousness to the mechanical brain; instead, the brain is a receiver of consciousness, which is recycled, replicated, entangled, and superimposed throughout the multiverse via microtubules of neurons of the brain and its electromagnetic field (see Figure 4).

\section{Theory and Methods}

Within Mocombe's theory of phenomenological structuralism (PS) the psychological assumptions are that human psychological development emerges from consciousness, which is an emergent fifth force of nature, a field of consciousness or consciousness field. Consciousness is an emergent fifth force of nature, a field of consciousness or the consciousness field, composed of quantum material substance/energy, psychion, the phenomenal property, qualia or informational content, of which is recycled/replicated/ entangled/superimposed throughout the multiverse and becomes embodied via the microtubules of neurons of brains and multiple worlds to constitute mind. Mind, composed of the personal and collective unconscious, and the emerging sense-experiences of the ego, qualia, held together or given uniformity and integrated as an I via the electromagnetic field of the brain is manifested in simultaneous, entangled, superimposed, and interconnecting material resource frameworks, multiple worlds, as praxis or practical consciousness of organic life, the content of which in-turn becomes the phenomenal properties, qualia, of material (subatomic particle energy, psychion) consciousness that is recycled/ replicated/entangled/superimposed throughout the multiverses upon matter disaggregation via the consciousness field. In other words, existence precedes essence; but essence is emergent and eternal, and comes to constitute a fifth force of nature, a field of consciousness for Being production, through the phenomenal properties, qualia (personal and collective unconscious sense experiences of past, present, and future existences), of neuronal subatomic particles, psychion, which are recycled/replicated/ superimposed/entangled throughout the multiverse and give human actors their initial (essential and unconscious) practical consciousness that they organize and reproduce in replicated, entangled, and superimposed material resource frameworks.

The brain is a receiver of consciousness from a consciousness field of the multiverse (see Figure 4). This consciousness field theory, CFT, of phenomenological structuralism differs from Johnjoe McFadden's (2020) conscious electromagnetic (EM) information (CEMI) field theory, which posits "that the seat of consciousness is simply the brain's EM field" (pg. 5), in that for me, the EM field of the brain is not the seat of consciousness; instead, it (the brain's EM field) serves more like a glue, which holds and integrates consciousness, which emerges from its on (force) field, together. In other words, consciousness emerges out of a field composed of subatomic particles, psychions, which have phenomenal properties (qualia) and become embodied in the neurons of brains that constitute an electromagnetic field during their firing that holds the psychions together as an individuated consciousness in order to experience objective reality. McFadden's attempt to hold on to dualism by substituting spirit in the matter/spirit argument with the EM field of the brain is tautological. That is holding on to energy and matter to give a dualist account of consciousness is not a dualist account; instead, it is an incomplete materialist account. My consciousness field theory (CFT) completes McFadden's materialist account regarding the nature and origins of consciousness by arguing for a physics, psychology, and sociology, which views consciousness as a fifth force of nature with its own field that is integrated and held together by the brain's EM field.

\section{Discussion and Conclusions}

On this physics, Mocombe builds his systemic philosophy, sociology, and psychology called phenomenological structuralism by tying the emergence of the field of consciousness, the consciousness field, composed of psychions to human sociological and psychological development and experiences, which constitute the phenomenal properties (qualia) of the psychions, which form the tripartite structure (ego, personal and collective unconscious) of the emerging human mind manifested as their practical activities. 
Psychologically speaking, in other words, the field of consciousness or consciousness field is the basis for psychological development. The field is an emergent fifth force of nature composed of the psychion, which is the energy substance that constitutes and transmits the ego essence of an individual person to the microtubules of neurons of brains (see Figure 4). The ego essence, psychion, is composed of all of the personal and collective sense experiences (personal and collective unconscious of the ego), the phenomenal properties or qualia, of the individual person, which becomes embodied in the microtubules of neurons in the brain as a result of matter aggregation across multiple simultaneous existing past/present/future worlds/universes. The structure of the mind, in the end, is composed of the ego and the personal and collective unconscious, which becomes embodied, as the qualia of psychions, via the microtubules of neurons of the aggregated brain and its EM field across replicated simultaneous past/present/future worlds of the multiverse. The EM field's "source is the electrical dipoles within the neuronal membranes caused by the motion of ions in and out of those membranes during action potentials and synaptic potentials. The periodic discharge of neurons-firing or action potentials-generates EMF waves that propagate out of the neuron and into the surrounding inter-neuronal spaces where they overlap and combine to generate the brain's global EM field that is routinely measured by brain scanning techniques such as electroencephalography (EEG) and magnetoencephalography (MEG)" (McFadden, 2020, pg. 5). The EM field integrates and holds together, like a glue, the ego essence, individuated consciousness of being, their psychion, which emerges out of its own force, the consciousness field. The ego, in other words, is the (material) essence, psychion, of the individual being. It is a composite of their past/present/future experiences, which emerge as the personal and collective unconscious, i.e., qualia, essence, of the ego. The latter two as such are the past/present/future biological and sociological sense experiences of the ego over all of its lived-experiences across the multiverse. Following matter disaggregation, the psychion, either collapses unto other versions of itself still in existence in the multiverse or returns to the consciousness field. The individual, doing embodiment, only becomes aware of itself as an ego with personal and collective tastes that individuates them from other objects and persons when they encounter conflict, throughout their lifespan, in becoming and being-in-worlds constituted via five (sociological) systems, i.e., mode of production, language, ideology, ideological apparatuses, and communicative discourse.

Future research must 1) continue to search for evidence of multiverses and other forms of existence tied to our present world, which will be similarly constituted as our own universe, and 2) proofs for the existence of the field of consciousness or consciousness field and its force, psychion, in order to falsify or verify Mocombe's overall theory of phenomenological structuralism against McFadden's CEMI theory.

\section{Acknowledgement}

None.

\section{Conflict of Interest}

No conflict of interest.

\section{References}

1. Althusser Louis (2001) Lenin and Philosophy and Other Essays. New York: Monthly Review Press, USA.

2. Althusser Louis, Étienne Balibar (1970) Reading Capital (Ben Brewster, Trans.). London: NLB, UK.

3. Anderson Tim (2020) "The Big Bang may be a Black Hole Inside Another Universe," retrieved from www.medium.com, accessed 27 July 2020.

4. Balibar, Etienne \& Immanuel Wallerstein (1991 [1988]) Race, Nation, Class:Ambiguous Identities. London: Verso, UK.

5. Buck-Morss Susan (2009) Hegel, Haiti, and Universal History. Pittsburgh: Universityof Pittsburgh Press, USA.

6. Cohen J (2002) Protestantism and Capitalism: The Mechanisms of Influence. NewYork: Aldine de Gruyter, USA.

7. Crothers Charles (2003) Technical Advances in General Sociological Theory: ThePotential Contribution of Post-Structurationist Sociology. Perspectives 26: 3-6.

8. Dahrendorf Ralf (1959) Class and Class Conflict in Industrial Society Stanford, California: Stanford University Press, USA.

9. Douglas M (1986) How Institutions Think. New York: Syracuse University Press, USA.

10. Fraser Nancy (1997) Justice Interruptus: Critical Reflections on the Postsocialist Condition. New York \& London: Routledge, USA

11. Gauthier Richard (2020) Big Bangs Created by Univon Particles from a Conscious Quantum Field-Towards the Next Scientific Revolution, retrieved from https://www.academia.edu, accessed 1 April 2020.

12. Hameroff, Stuart and Roger Penrose (2014) Consciousness in the Universe: A Review of the 'Orch OR' theory. Physics of Life Reviews 11: 39-78.

13. Holloway Joseph E (ed.) (1990a) Africanisms in American Culture. Bloomington and Indianapolis: Indiana University Press, USA.

14. Holloway Joseph E (1990b) The Origins of African-American Culture. In Joseph Holloway (Ed.), Africanisms in American Culture (19-33). Bloomington and Indianapolis: Indiana University Press, USA.

15. Horkheimer Max, Theodor W Adorno (2000 [1944]. Dialectic of Enlightenment (John Cumming, Trans.). New York: Continuum, USA.

16. Hudson, Kenneth, Andrea Coukos (2005) The Dark Side of the Protestant Ethic: A Comparative Analysis of Welfare Reform. Sociological Theory 23(1): $1-24$

17. James CLR (1986) The Black Jacobins: Toussaint L' Ouverture and the San Domingo Revolution. Vintage

18. Karenga, Maulana (1993) Introduction to Black Studies. California: The University of Sankore Press, USA.

19. Kellner Douglas (2002) Theorizing Globalization. Sociological Theory 20: 285-305.

20. Kurtz Lester R (2007) Gods in the Global Village: The World's Religions in Sociological Perspective. California: Sage Publications, USA.

21. Lukács Georg (1971) History and Class Consciousness: Studies in Marxist Dialectics (Rodney Livingstone, Trans.). Cambridge, Massachusetts: The MIT Press., USA

22. Lukács, Georg (2000) A Defence of History and Class Consciousness: Tailism and the Dialectic (Esther Leslie, Trans.). London and New York: Verso, USA. 
23. Marcuse Herbert (1964) One-Dimensional Man. Boston: Beacon Press, USA.

24. Marcuse, Herbert (1974) Eros and Civilization: A Philosophical Inquiry into Freud. Boston: Beacon Press, USA.

25. Marx Karl and Friedrich Engels (1964). The Communist Manifesto. London, England: Penguin Books, UK.

26. Marx, Karl (1992 [1867]) Capital: A Critique of Political Economy (Volume 1, Samuel Moore and Edward Aveling, Trans.). New York: International Publishers, USA.

27. Marx, Karl (1998 [1845]) The German Ideology. New York: Prometheus Books, USA.

28. McFadden, Johnjoe (2020) "Integrating Information in the Brain's EM Field: the cemi Field Theory of Consciousness", Neuroscience of Consciousness 6 (1): 1-13.

29. McMichael, Philip (2008) Development and Social Change: A Global Perspective. Los Angeles, California: Sage Publications, USA.

30. Mocombe Paul C (2019) The Theory of Phenomenological Structuralism. United Kingdom: Cambridge Scholars Publishing, UK.

31. Mocombe Paul C (2016) The Vodou Ethic and the Spirit of Communism: The Practical Consciousness of the African People of Haiti. Maryland: University Press of America, USA.

32. Mocombe Paul C (2009) The Soul-less Souls of Black Folk: A Sociological Reconsideration of Black Consciousness as Du Boisian Double
Consciousness. Maryland: University Press of America. Ortner, Sherry (1984). Theory in Anthropology Since the Sixties, Comparative Studies in Society and History 26: 126-166.

33. Patterson, Orlando (1982) Slavery and Social Death: A Comparative Study. Cambridge, Massachusetts: Harvard University Press, USA.

34. Ramsey Kate (2011) The Spirits and the Law: Vodou and Power in Haiti. Chicago: University of Chicago Press, USA.

35. Rubin, Vera (Ed.) (1960) Caribbean Studies: A Symposium. Seattle: University of Washington Press, USA.

36. Sklair, Leslie (1995) Sociology of the Global System. Baltimore: Westview Press, USA.

a. Smith MG (1960) The African Heritage in the Caribbean. In Vera Rubin (Ed.), Caribbean Studies: A Symposium (pp. 34-46). Seattle: University of Washington Press, USA.

37. Wallerstein Immanuel (1982) The Rise and Future Demise of the World Capitalist System: Concepts for Comparative Analysis. In Hamza Alavi and Teodor Shanin (Eds.), Introduction to the Sociology of "Developing Societies. New York: Monthly Review Press, pp. 29-53.

38. Weber Max (1958 [1904-1905]) The Protestant Ethic and the Spirit of Capitalism (Talcott Parsons, Trans.). New York: Charles Scribner's Sons, USA 